\title{
Estimation of Building's Life Cycle Carbon Emissions Based on Life Cycle Assessment and Building Information Modeling: A Case Study of a Hospital Building in China
}

\author{
Kun Lu1*, Hongyu Wang ${ }^{2}$ \\ ${ }^{1}$ School of Civil Engineering, Hefei University of Technology, Hefei, China \\ ${ }^{2}$ Urban Planning and Design Center, Peking University, Beijing, China \\ Email: *lukun@mail.hfut.edu.cn
}

How to cite this paper: Lu, K., \& Wang, H. Y. (2019). Estimation of Building's Life Cycle Carbon Emissions Based on Life Cycle Assessment and Building Information Modeling: A Case Study of a Hospital Building in China. Journal of Geoscience and Environment Protection, 7, 147-165. https://doi.org/10.4236/gep.2019.76013

Received: May 27, 2019

Accepted: June 27, 2019

Published: June 30, 2019

Copyright $\odot 2019$ by author(s) and Scientific Research Publishing Inc. This work is licensed under the Creative Commons Attribution International License (CC BY 4.0).

http://creativecommons.org/licenses/by/4.0/

\begin{abstract}
Throughout the life cycle, the buildings emit a great deal of carbon dioxide into the atmosphere, which directly leads to aggravation in the greenhouse effect and becomes a severe threat to the environment and humans. Researchers have made numerous efforts to accurately calculate emissions to reduce the life cycle carbon emissions of residential buildings. Nevertheless, there are still difficulties in quickly estimating carbon emissions in the design stage without specific data. To fill this gap, the study, based on Life Cycle Assessment (LCA) and Building Information Modeling (BIM), proposed a quick method for estimating Building's Life Cycle Carbon Emissions (BLCCE). Taking a hospital building in Chuzhou City, Anhui Province, China as an example, it tested its possibility to estimate BLCCE. The results manifested that: 1) the BLCCE of the project is $40,083.56 \mathrm{tCO}_{2}$-eq, and the carbon emissions per square meter per year are $\left.119.91 \mathrm{kgCO}_{2}-\mathrm{eq} /\left(\mathrm{m}^{2} \cdot \mathrm{y}\right) ; 2\right)$ the stage of construction, operational and demolition account for $7.90 \%, 91.31 \%$, and $0.79 \%$ of BLCCE, respectively; 3 ) the annual carbon emissions per square meter of hospital are apparently higher than that of villa, residence, and office building, due to larger service population, longer daily operation time, and stricter patient comfort requirements. Considering the lack of BLCCE research in Chinese hospitals, this case study will provide a valuable reference for the estimated BLCCE of hospital building.
\end{abstract}

\section{Keywords}

Carbon Emissions, Life Cycle Assessment, Building Information Modeling, Hospital Building 


\section{Introduction}

The global warming effect has attracted increasing attention all over the world (Gustavsson, Joelsson, \& Sathre, 2010), among which carbon emissions are considered to be one of the underlying causes of global warming. Therefore, carbon emissions are progressively being used to quantify human impact on the environment (Wiedmann \& Minx, 2008). As a core industry, the construction industry makes up 30\% - 40\% of all industries' carbon emissions (Baek, Tae, Kim, \& Shin, 2016; Cabeza, Rincón, Vilariño, Pérez, \& Castell, 2014; Cubi, Doluweera, \& Bergerson, 2015). For the sake of slashing building's life cycle carbon emissions (BLCCE), BLCCE calculation needs to be addressed first (Lee, Tae, \& Kim, 2018).

Among the existing methods, Life Cycle Assessment (LCA) is extensively used to measure and evaluate the environmental impact of a particular product throughout its life cycle (Klüppel, 2005). The development of the Building Information Model (BIM) has contributed rapid and efficient methods for the implementation of LCA in the recent years (Rezaei, Bulle, \& Lesage, 2019; Santos, Costa, Silvestre, \& Pyl, 2019). Many scholars used BIM and LCA to calculate building carbon emissions, and have achieved immense advance (Gan et al., 2018; Peng, 2016; Yang, Hu, Wu, \& Zhao, 2018). The purpose of calculating carbon emissions is to reduce carbon emissions, while carbon emission reduction needs to adopt abatement measures at the design phase of the building (Häkkinen, Kuittinen, Ruuska, \& Jung, 2015; Zhu, Chew, Lv, \& Wu, 2013). However, for the engineering design phase with limited data, it is still problematic to estimate the BLCCE.

In terms of building types, many scholars studied the BLCCE of villas (Yang et al., 2018), residential building (Li, Cui, \& Lu, 2016; Zhang \& Wang, 2015; Zhang, Zheng, Zhang, Chen, \& Wang, 2016), office buildings (Peng, 2016; Zhang \& Wang, 2015). However, the hospital building, as a building that is saddled with the urban medical system, has undergone tremendous variations in architectural nature compared with civil buildings or ordinary public buildings. But regrettably, the study of hospital building's BLCCE is unprecedented.

Based on these above, this paper applied LCA theory and BIM technology to put forward the estimation theory of the BLCCE. Simultaneously, a hospital building in Chuzhou City, Anhui Province, China, was taken as an example to estimate its BLCCE by using the theoretical method proposed in this paper. This study will help to estimate carbon emissions during the design phase with partial data deficiencies and conduct theoretical support for the adoption of low-carbon design and low-carbon decision-making. It will also make a contribution to serve as references for analyzing the BLCCE of the hospital building.

\section{Literature Review}

\subsection{Building's Life Cycle Carbon Emissions}

Building's life cycle carbon emissions (BLCCE) refers to the carbon emissions 
generated by the building throughout its life cycle. The accounting of Carbon emissions (also can be converted into greenhouse gas emission or $\mathrm{CO}_{2}$ emissions) often uses Carbon dioxide equivalent $\left(\mathrm{CO}_{2}\right.$-eq) as the accounting unit (Turner \& Collins, 2013). The calculation of carbon dioxide equivalent $\left(\mathrm{CO}_{2}\right.$-eq) takes into account the collective contribution of greenhouse gases (including $\mathrm{CO}_{2}, \mathrm{CH}_{4}, \mathrm{NO}_{2}$, etc.) (Gan et al., 2018). Thereby, carbon dioxide equivalent was employed as the calculation unit in this paper.

The BLCCE consists of three stages: 1) construction stage; 2) operational stage; 3) demolition stage (Peng, 2016). The carbon emissions at the construction stage mainly include material production, material transportation, and construction on site (Wan Omar, Doh, \& Panuwatwanich, 2014; Yang et al., 2018). The carbon emissions at the operational stage originate within the energy consumption are produced by HVAC (heating, ventilation, air conditioning), lighting, water supplying, and equipment use (Roh \& Tae, 2017), as well as refurbishment (Yang et al., 2018). Moreover, it varies drastically with climatic conditions, comfort requirements, and operating schedules (Ramesh, Prakash, \& Shukla, 2010). Carbon emissions at the demolition stage are chiefly derived from demolition and refurbishment. The composition of BLCCE is as shown in Figure 1.

Although there were a multitude of studies have concerned calculations of life cycle carbon emissions, estimating the BLCCE remains obstructive due to the lack of data or complexity of information processing (Gustavsson et al., 2010). These research gaps are accompanied by the entire life cycle of the building. Firstly, at the construction stage, diverse materials, various types of machines, and chaotic construction techniques are mixed together in a dense time period (Li, Zhu, \& Zhang, 2010). Secondly, energy consumption at the operational stage is challenging to calculate due to the disparate lifestyle and comfort requirements of different residents (Yang et al., 2018). Thirdly, at the demolition stage,

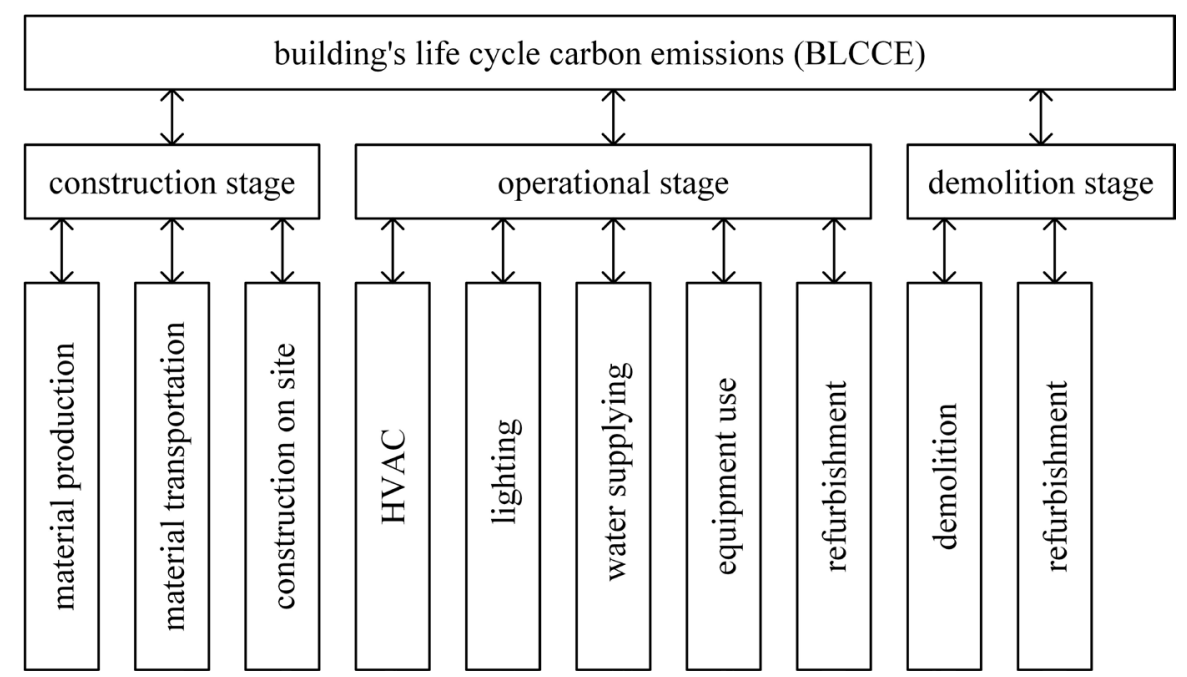

Figure 1. Composition of building's life cycle carbon emissions (Peng, 2016; Yang et al., 2018). 
the means of demolition and the method of recovery are often fail to predict, and the estimation at this stage is full of obstacles.

\subsection{Application of LCA and BIM in BLCCE}

Life Cycle Assessment (LCA) is a method of assessing environmental and social impacts (Norris, 2001). According to the ISO 14041 Standard, LCA research is divided into four steps (Klüppel, 1998): 1) goal and scope definition; 2) inventory analysis; 3 ) environment impact assessment; 4 ) interpretation.

In the past few years, BIM has become a highly popular term and concept in architecture, engineering, and construction (Shin \& Cho, 2015). The definition of BIM is "a set of interrelating policies, processes and technologies" that have resulted in a systematic approach to the management of key information about building design and project data appeared in a digital format throughout the building life cycle (Penttilä, 2006; Wong \& Zhou, 2015).

Many researchers have tried to apply BIM to LCA (Shin \& Cho, 2015). Many scholars presumed that connecting BIM and LCA software will eliminate the need for manual data input and remarkably accelerate the establishment of LCA model (Santos et al., 2019; Yang et al., 2018). Based on the rapidity of BIM, BIM is frequently adopted in LCA analysis of building carbon emissions. Basbagill et al. (2013) attempted to significantly reduce the actual carbon footprint with material and thickness decisions made through "BIM-enabled embodied impact feedback and prescription”. Han et al. (2014) proposed a building system optimization framework aimed at minimizing the life cycle cost of BIM-based energy consumption analysis. Shadram et al. (2016) constructed a model to evaluate the embodied energy of the material through the integration of BIM. Peng (2016) presented a calculation method for BLCCE based on Ecotect and BIM. D. Li et al. (2016) developed an automatic estimation system for life cycle carbon emissions of residential buildings. Yang et al. (2018) undertook a case study on carbon footprint accounting of a residential building based on BIM and LCA.

From the above literature review, it can be concluded that some scholars have offered methods for calculating carbon emissions based on BIM and LCA. Furthermore, there were also known the approaches to estimate carbon emissions. However, on the one hand, the estimation method of carbon emission based on BIM and LCA theory has not been formed. On the other hand, most of the current research was focused on villas, residential buildings, and office buildings. There is no research has been carried out on the BLCCE of a hospital building that consumes a vast amount of energy.

\section{Methods}

\subsection{Overview}

According to the above analysis, the BLCCE is composed of carbon emissions at the construction stage, the operational stage, and the demolition stage. The total BLCCE is calculated by the Formula (1). $C_{\text {tot }}, C_{\text {con }}, C_{\text {ope }}$, and $C_{\text {dem }}$ are corres- 
ponding to the carbon emissions of the life cycle, the construction stage, the operational stage, and the demolition stage, respectively.

$$
C_{\text {tot }}=C_{\text {con }}+C_{\text {ope }}+C_{\text {dem }}
$$

A building involves various fields of expertise, such as architecture, structure, facility, equipment, electricity, and water supply system (Maia, Mêda, \& Freitas, 2015), all of which have an impact on the amount of material and fuel in building's life cycle. The quantitative data on materials and fuels is decisive for the final outcome of BLCCE, as a result, the data sources are crucial in particular (Shin \& Cho, 2015). In addition, the characteristics of each material should be listed and described, including material density, unit of measurement, manufacturing process, and production site. Only with this data can the corresponding carbon emission coefficient be matched. Therefore, the corresponding carbon emission coefficient database should be established before calculating the carbon emission.

At the construction stage, carbon emissions can be estimated by the bill of quantities method. Construction quotas are used to account for resource consumption and construction costs in China (Yang et al., 2018). Therefore, BIM5D software and construction quota can be employed to calculate the amount of engineering consumed at the construction stage, so as to calculate carbon emissions at the construction stage. Carbon emissions at the operational stage mainly come from the energy consumption generated by HVAC (heating, ventilation, air conditioning), lighting, water supplying, and equipment use. This energy consumption is represented by fuel consumption and electricity consumption. Carbon emissions at the demolition stage are estimated according to the carbon emissions at the construction stage. The information required for each stage and its sources are shown in Table 1.

\subsection{Estimation Method at the Construction Stage}

The bill of quantities is used to estimate carbon emissions at the construction stage. The carbon emissions at the construction stage are composed of sub-item project and measure project (Formula (2)). The carbon emission of sub-item project or measure project is equal to the carbon emissions coefficient of quota multiplied by the quantity of quota (Formula (3)). The carbon emission coefficient

Table 1. Information required and its data sources.

\begin{tabular}{ccc}
\hline Stage & Information required for LCA & Data sources \\
\hline construction & amount of materials & BIM5D software \\
amount of working days & bill of quantities \\
amount of mechanical class & life cycle database \\
amount of fuel consumption & BIM operation simulation software \\
demolition & amount of electricity & life cycle database \\
\end{tabular}


of quota is the carbon emission produced by the unit quota, and its value is equal to the number of man-days, material and mechanical multiplied by their carbon emission coefficient (Formula (4)). The quantities of sub-item project, measure project, and quota come from BIM5D software. Carbon emission coefficient is selected from the carbon emission coefficient database.

$$
\begin{gathered}
C_{\text {con }}=\sum C_{\mathrm{sp}}+\sum C_{\mathrm{mp}} \\
C_{\mathrm{sp}, \mathrm{mp}}=\sum C C_{\mathrm{q}} \times Q_{\mathrm{q}} \\
C C_{\mathrm{q}}=\sum C C_{\mathrm{md}} \times Q_{\mathrm{md}}+\sum C C_{\mathrm{mat}} \times Q_{\mathrm{mat}}+\sum C C_{\text {mech }} \times Q_{\text {mech }}
\end{gathered}
$$

In the Formulas (2)-(4): $C_{\mathrm{sp}}$ and $C_{\mathrm{mp}}$ represent carbon emissions generated by sub-item project and measure project separately; $C C_{\mathrm{q}}, C C_{\mathrm{md}}, C C_{\mathrm{mat}}$, and $C C_{\mathrm{mech}}$ represent the carbon emission coefficient of quota, man-days, material, and machine class separately; $Q_{\mathrm{q}}, Q_{\mathrm{md}}, Q_{\mathrm{mat}}$, and $Q_{\text {mech }}$ represent the amount of quota, man-days, material, and machine class separately.

\subsection{Estimation Method at the Operational Stage}

As an estimation method, the energy required for refurbishment at the operational stage is negligible, as it accounts for only about 5 per cent of the life cycle energy consumption (Sartori \& Hestnes, 2007; Yang et al., 2018). Carbon emissions at the operational stage mainly come from the energy consumption generated by HVAC, lighting, water supplying and equipment use. This energy consumption is represented by fuel consumption and electricity consumption. If sustainable energy is used at the operational stage, this part should be deducted. The estimation formulas of carbon emissions at the operational stage are listed in the Formulas ((5), (6)).

$$
\begin{gathered}
C_{\text {ope }}=C_{\text {sy }} \times Y \\
C_{\text {sy }}=C_{\mathrm{e}}+C_{\mathrm{f}}+C_{\mathrm{re}}
\end{gathered}
$$

In the Formulas $((5),(6)), C_{\text {sy }}$ represents the annual carbon emissions generated during the building use phase; $C_{\mathrm{e}}$ represents the annual carbon emissions generated by building electricity; $C_{\mathrm{f}}$ represents carbon emissions generated by the annual fuel consumption of the building; $C_{\text {re }}$ represents the annual reduction in carbon emissions from sustainable energy use; $Y$ is the service life at the operational stage, generally 50 years.

\subsection{Estimation Method at the Demolition Stage}

At the demolition stage, the bill of quantities method should be used to calculate the carbon emissions, and the calculation method should be the same as the construction stage. However, at the demolition stage, the data on the demolition workload stays unspecified at times. Many scholars deemed that the carbon emissions at the demolition stage can be approximately equal to $10 \%$ of the construction stage (Cai, Wang, \& Fu, 2010; Hua et al., 2014; Zhong, 2005). Besides, researchers pointed out that the demolition stage accounts for about only $1 \%$ of 
BLCCE (Sartori \& Hestnes, 2007; Zhang \& Wang, 2015), thus the estimation at this stage would not affect the estimation of BLCCE (Zhang \& Wang, 2015). For convenience, this calculation can be simplified to the form of Formula (7) to estimate the carbon emissions at the demolition stage.

$$
C_{\text {dem }}=C_{\text {con }} \times 10 \%
$$

\section{Case Study and Results}

\subsection{Background Information of the Target Building}

Mingguang People's Hospital Building is located in Chuzhou City, Anhui Province, China. It is a public building supported by a reinforced concrete frame structure system with a gross floor area (GFA) of $6367 \mathrm{~m}^{2}$ and a base area of $1703 \mathrm{~m}^{2}$. The building has 4 stories with a height of $15.9 \mathrm{~m}$, can accommodate 102 beds, and has a design service life of 50 years. The construction engineering grade is two, the building fire resistance grade is two, and the seismic fortification intensity is 6 degree. The building is heated in winter by fossil energy.

\subsection{Carbon Emissions Coefficient Database}

Before calculating carbon emissions, establishing carbon emissions coefficient database is necessary. According to carbon emission coefficient mentioned in the literature and the "standard for measuring, accounting and reporting of carbon emission from building, CECS 374, 2014" authorized by China Engineering Construction Industry Association, the database of carbon emissions coefficient was established. Since the case is located in Anhui Province, China, the carbon emission coefficient selected gave priority to the actual local situation. Partial carbon emission coefficients in the database are shown in Table 2.

\subsection{Establishment of Building Information Model}

The core modeling software of BIM selected in this paper is Revit2017 (see Figure 2). Revit2017 is developed by Autodesk Company, which is regarded by

Table 2. Partial carbon emission coefficient in the database.

\begin{tabular}{cccc}
\hline Type & Characteristics & Unit & Carbon coefficient \\
\hline electricity & Anhui province & $\mathrm{kgCO}_{2}$-eq $/ \mathrm{kW} \cdot \mathrm{h}$ & 0.928 \\
diesel & & $\mathrm{kgCO}_{2}$-eq $/ \mathrm{kg}$ & 3.096 \\
concrete & $\mathrm{C} 20$ & $\mathrm{kgCO}_{2}$-eq $/ \mathrm{m}^{3}$ & 239.190 \\
concrete & $\mathrm{C} 25$ & $\mathrm{kgCO}_{2}$-eq $/ \mathrm{m}^{3}$ & 289.440 \\
brick & hollow brick & $\mathrm{kgCO}_{2}$-eq $/ 100$ blocks & 150.980 \\
steel & reinforced & $\mathrm{kgCO}_{2}$-eq $/ \mathrm{kg}$ & 2.103 \\
man-day & moderate labour & $\mathrm{kgCO}_{2}$-eq $/$ day & 2.420 \\
concrete mixer & $350 \mathrm{~L}$ & $\mathrm{kgCO}_{2}$-eq $/$ class & 72.295 \\
unloading car & $4 \mathrm{t}$ & $\mathrm{kgCO}_{2}$-eq $/$ class & 46.340 \\
\hline
\end{tabular}


many experts as the most commonly used BIM modeling software in the field of architecture, engineering, and construction (Inyim, Rivera, \& Zhu, 2014; Wong \& Kuan, 2014). It should be noted that BIM should qualify the required level of details so that the relevant information can be extracted directly and accurately. Typically, the level of details of BIM should range from 200 to 300 in the study of LCA (Soust-Verdaguer, Llatas, \& García-Martínez, 2017). Therefore, the level of details of BIM in this case was 300. Glondon GTJ2018 was selected as BIM quantities software in this case. In order to improve the data interoperability between Autodesk Revit2017 and Glondon GTJ2018, the BIM model was constructed according to the BIM Guide by Glondon Company.

When Revit2017 was imported into GTJ2018, there was component loss due to the compatibility of data. Therefore, it is necessary to supplement the graphics information and steel bar data of the building. The BIM quantities model in GTJ2018 was checked and modified to ensure it is right (see Figure 3). Glondon

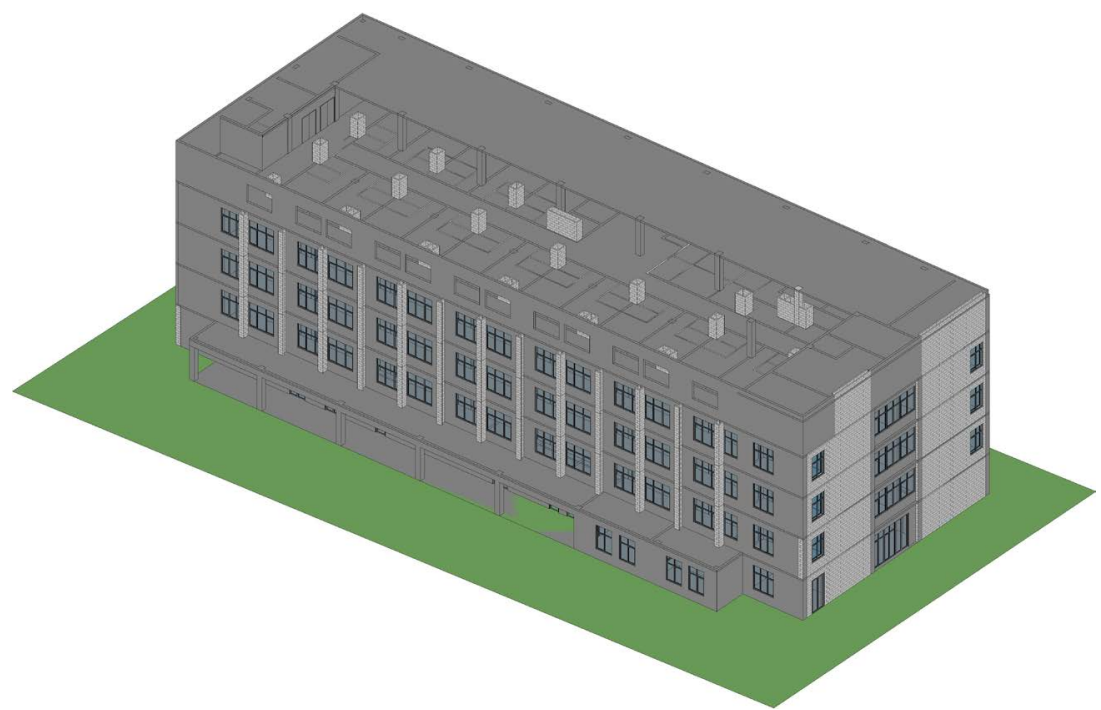

Figure 2. Building information modeling created by Revit2017.

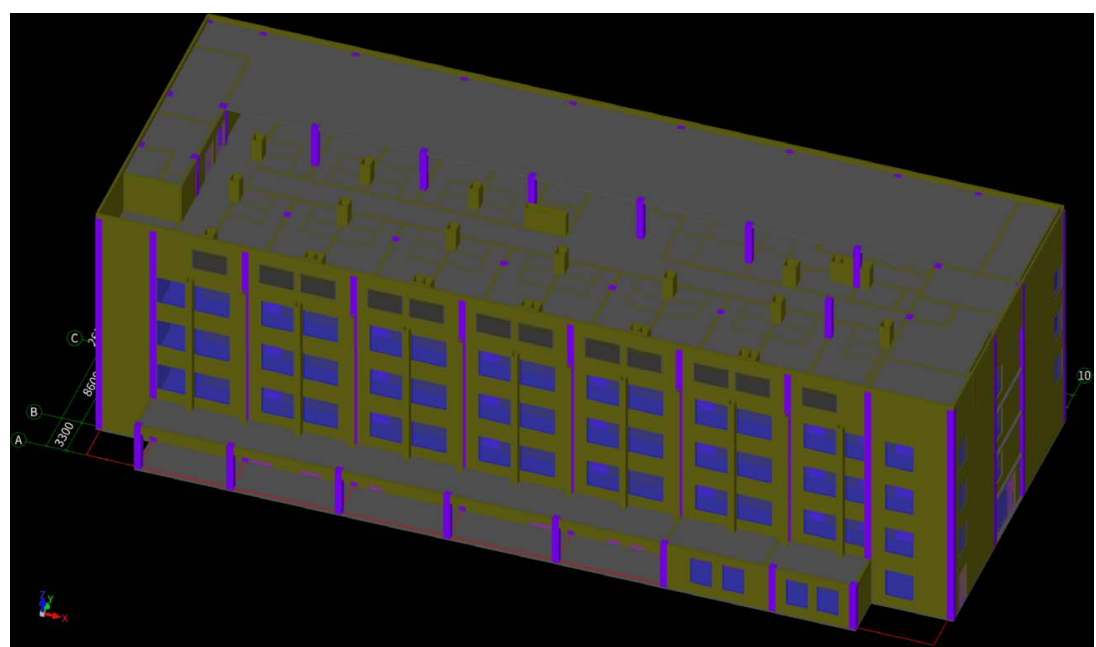

Figure 3. BIM quantities model in GTJ2018. 
software is a commonly used software for calculating engineering quantities in China. It can calculate engineering quantities and export bill of quantities. This study followed the "2013 Code of Valuation with Bill Quantity of Construction Works" released by China's Ministry of Housing and Urban-Rural Development, the "2013 Construction Engineering Valuation Quota of Anhui" and the "2013 Construction Machinery Cost Quota of Anhui” released by Anhui Provincial Construction Department.

\subsection{Estimated Carbon Emissions at the Construction Stage}

Before calculating the carbon emissions at the construction stage, the study needed to calculate the quota carbon emission coefficient $\left(C C_{\mathrm{q}}\right)$, which represents the carbon emissions generated by unit quota. Taking the quota A4-17 (see Table 3) and A10-31 (see Table 4) as examples, how to calculate the quota carbon emission coefficient $C C_{\mathrm{q}}$ is presented.

Table 3. Quota A4-17 carbon emission coefficient.

\begin{tabular}{|c|c|c|c|c|c|}
\hline \multirow{2}{*}{$\begin{array}{l}\text { Quota number } \\
\text { Quota name }\end{array}$} & \multicolumn{4}{|l|}{ A4-17 } & \multirow[t]{2}{*}{ Unit: $\mathrm{m}^{3}$} \\
\hline & \multicolumn{4}{|c|}{ Single beam, continuous beam, frame beam } & \\
\hline Kind & Name & Unit & Consumption & $\mathrm{CO}_{2}$-eq coefficient & Total \\
\hline man-day & man-day & day & 1.43 & 2.42 & 3.46 \\
\hline \multirow[t]{2}{*}{ material } & concrete $\mathrm{C} 20$ & $\mathrm{~m}^{3}$ & 1.02 & 239.19 & 242.78 \\
\hline & water & $\mathrm{m}^{3}$ & 1.20 & 0.91 & 1.09 \\
\hline \multirow[t]{2}{*}{ machinery } & concrete mixer $350 \mathrm{~L}$ & class & 0.06 & 72.29 & 4.56 \\
\hline & Concrete vibrator plug in & class & 0.13 & 4.04 & 0.51 \\
\hline \multicolumn{5}{|c|}{ Total $\left(\mathrm{kgCO}_{2}-\mathrm{eq} / \mathrm{m}^{3}\right)$} & 252.39 \\
\hline
\end{tabular}

Table 4. Quota A10-31 carbon emission coefficient.

\begin{tabular}{|c|c|c|c|c|c|}
\hline \multirow{2}{*}{$\begin{array}{l}\text { Quota number } \\
\text { Quota name }\end{array}$} & \multicolumn{3}{|l|}{ A10-31 } & \multicolumn{2}{|c|}{ Unit: $10 \mathrm{~m}^{2}$} \\
\hline & \multicolumn{5}{|c|}{ Rectangular beam composite wood formwork } \\
\hline Kind & Name & Unit & Consumption & $\mathrm{CO}_{2}$-eq coefficient & Total \\
\hline man-days & man-days & day & 3.187 & 2.42 & 7.71 \\
\hline \multirow[t]{5}{*}{ material } & composite wood form & $\mathrm{m}^{2}$ & 2.200 & 0.19 & 0.42 \\
\hline & Steel support & $\mathrm{kg}$ & 6.699 & 2.00 & 13.40 \\
\hline & wooden support & $\mathrm{m}^{3}$ & 0.015 & 0.19 & 0.003 \\
\hline & steel nails & $\mathrm{kg}$ & 0.819 & 2.00 & 1.64 \\
\hline & galvanized iron wire & $\mathrm{kg}$ & 0.030 & 2.00 & 0.06 \\
\hline \multirow[t]{3}{*}{ machinery } & unload truck $4 \mathrm{t}$ & class & 0.017 & 46.34 & 0.79 \\
\hline & truck crane $5 \mathrm{t}$ & class & 0.014 & 23.40 & 0.33 \\
\hline & woodworking circular saw 500 & class & 0.033 & 42.44 & 1.40 \\
\hline \multicolumn{5}{|c|}{ Total $\left(\mathrm{kgCO}_{2}-\mathrm{eq} / 10 \mathrm{~m}^{2}\right)$} & 25.75 \\
\hline
\end{tabular}


After the quota carbon emission coefficient was calculated, the carbon emission of the sub-item project or measure project can be calculated through the quota carbon emission coefficient, project quantities, and quota quantities (project quantity and quota quantity come from GTJ2018). Examples of carbon emissions from the sub-item project and measures project are shown in Table 5 and Table 6 , respectively.

Table 5. Calculation of carbon emissions from sub-item project 10101003001.

\begin{tabular}{|c|c|c|c|c|c|}
\hline \multirow{2}{*}{$\begin{array}{l}\text { Project number } \\
\text { Project name }\end{array}$} & \multirow{2}{*}{$\begin{array}{l}10101003001 \\
\text { Earth excavation of foundation }\end{array}$} & \multicolumn{4}{|c|}{ Project quantities: 1143.88} \\
\hline & & Unit: & & & \\
\hline Quota number & Quota name & Unit & Quota quantities & Quota coefficient & Subtotal \\
\hline A1-143 & hydraulic crawler excavator (put it) & $\mathrm{m}^{3}$ & 456.87 & 1.87 & 853.03 \\
\hline A1-144 & hydraulic crawler excavator (not put in) & $\mathrm{m}^{3}$ & 842.57 & 1.46 & 1233.78 \\
\hline A1-181 & dump truck transport soil $8 \mathrm{t}$ & $\mathrm{m}^{3}$ & 456.87 & 14.59 & 6663.88 \\
\hline Total $\left(\mathrm{kgCO}_{2}\right.$-eq $)$ & & & & & 8750.69 \\
\hline
\end{tabular}

Table 6. Calculation of carbon emissions from measure project 60108000001 .

\begin{tabular}{|c|c|c|c|c|c|}
\hline \multirow{3}{*}{$\begin{array}{l}\text { Project number } \\
\text { Project name } \\
\text { Quota number }\end{array}$} & \multirow{3}{*}{$\begin{array}{l}60108000001 \\
\text { Formwork and bracket } \\
\text { Quota name }\end{array}$} & \multicolumn{4}{|c|}{ Project quantities: 1} \\
\hline & & \multicolumn{4}{|c|}{ Unit: item } \\
\hline & & Unit & Quota quantities & Quota coefficient & Subtotal \\
\hline A10-1 & concrete cushion composite steel formwork & $10 \mathrm{~m}^{2}$ & 8.46 & 30.35 & 256.65 \\
\hline A10-7 & independent foundation, pile cap composite wood formwork & $10 \mathrm{~m}^{2}$ & 59.31 & 24.06 & 1427.11 \\
\hline A $10-29$ & foundation beam composite wood formwork & $10 \mathrm{~m}^{2}$ & 113.15 & 23.66 & 2677.61 \\
\hline A10-11 & beamless wood formwork for full floor foundation & $10 \mathrm{~m}^{2}$ & 0.43 & 21.21 & 9.09 \\
\hline A10-1 & concrete cushion composite steel formwork & $10 \mathrm{~m}^{2}$ & 1.72 & 30.35 & 52.21 \\
\hline A $10-26$ & structure column composite formwork & $10 \mathrm{~m}^{2}$ & 216.76 & 22.76 & 4934.61 \\
\hline A $10-21$ & rectangular column composite wood formwork & $10 \mathrm{~m}^{2}$ & 130.11 & 29.60 & 3851.39 \\
\hline A10-37 & ring beam composite wood formwork & $10 \mathrm{~m}^{2}$ & 13.64 & 16.21 & 221.08 \\
\hline A $10-39$ & beam compound wood formwork & $10 \mathrm{~m}^{2}$ & 8.52 & 21.09 & 179.69 \\
\hline A $10-42$ & straight wall composite wood formwork & $10 \mathrm{~m}^{2}$ & 6.13 & 29.07 & 178.11 \\
\hline A $10-44$ & elevator shaft wall composite wood formwork & $10 \mathrm{~m}^{2}$ & 10.59 & 30.72 & 325.44 \\
\hline A $10-50$ & beam board composite wood formwork & $10 \mathrm{~m}^{2}$ & 1195.92 & 22.30 & 26665.53 \\
\hline A $10-31$ & rectangular beam composite wood formwork & $10 \mathrm{~m}^{2}$ & 78.48 & 25.75 & 2020.74 \\
\hline A10-65 & bar board composite wood formwork & $10 \mathrm{~m}^{2}$ & 14.30 & 30.96 & 442.74 \\
\hline A10-60 & cantilever board straight composite wood formwork & $10 \mathrm{~m}^{2}$ & 0.56 & 46.10 & 25.60 \\
\hline A $10-67$ & gutter timber formwork with overhanging eaves & $10 \mathrm{~m}^{2}$ & 38.30 & 24.98 & 956.73 \\
\hline A $10-58$ & stair composite wood formwork & $10 \mathrm{~m}^{2}$ & 31.80 & 41.93 & 1333.44 \\
\hline A10-71 & top pressing composite wood formwork & $10 \mathrm{~m}^{2}$ & 22.22 & 26.18 & 581.71 \\
\hline A10-66 & small component wooden formwork & $10 \mathrm{~m}^{2}$ & 26.50 & 24.50 & 649.09 \\
\hline A $10-74$ & bench board & $10 \mathrm{~m}^{2}$ & 4.46 & 8.12 & 36.25 \\
\hline Total $\left(\mathrm{kgCO}_{2}\right.$-eq $)$ & & & & & 46824.83 \\
\hline
\end{tabular}


After calculating the carbon emissions of each sub-item project and measure project, these carbon emissions were aggregated to acquire the total carbon emissions at the construction stage (see Table 7). The project coefficient in Table 7 is the evaluation index obtained by dividing the subtotal of the project by the project quantities, and it represents the carbon emissions generated by the unit sub-item project or measure project. In this case, the estimated carbon emissions at the construction stage are $3,166,873.38 \mathrm{kgCO}_{2}$-eq, namely, 3166.87 $\mathrm{tCO}_{2}$-eq.

\subsection{Estimated Carbon Emissions at the Operational Stage}

Carbon emissions at the operational stage come from refurbishment and the energy consumption generated by HVAC, lighting, water supplying, and equipment use. Among them, refurbishment can be ignored according to the above analysis. The energy consumption generated by HVAC, lighting, water supplying,

Table 7. Summary of carbon emissions at the construction stage.

\begin{tabular}{|c|c|c|c|c|c|}
\hline Project number & Project name & Unit & $\begin{array}{c}\text { Project } \\
\text { quantities }\end{array}$ & $\begin{array}{c}\text { Project } \\
\text { coefficient }\end{array}$ & Subtotal \\
\hline \multicolumn{6}{|l|}{ (sub-item project) } \\
\hline 010101001001 & flat ground & $\mathrm{m}^{2}$ & 1563.40 & 0.45 & 710.07 \\
\hline 010101003001 & earth excavation of foundation & $\mathrm{m}^{3}$ & 1143.88 & 7.65 & 8750.69 \\
\hline 010103001001 & foundation earthwork backfill & $\mathrm{m}^{3}$ & 706.36 & 2.37 & 1670.58 \\
\hline 010103001002 & indoor earthwork backfill & $\mathrm{m}^{3}$ & 107.22 & 2.13 & 227.92 \\
\hline 010301001001 & brick foundation & $\mathrm{m}^{3}$ & 4.50 & 319.89 & 1439.49 \\
\hline 010302004001 & filler wall (mixed-water brick) & $\mathrm{m}^{3}$ & 15.97 & 338.98 & 5413.56 \\
\hline 010302004002 & filler wall (thickness 180) & $\mathrm{m}^{3}$ & 972.46 & 187.96 & 182778.78 \\
\hline 010401002001 & isolated footing & $\mathrm{m}^{3}$ & 281.07 & 299.18 & 84089.48 \\
\hline 010403001001 & foundation beam & $\mathrm{m}^{3}$ & 143.23 & 356.79 & 51103.60 \\
\hline 010402001003 & rectangular column & $\mathrm{m}^{3}$ & 56.92 & 453.41 & 25808.34 \\
\hline 010402001001 & constructional column & $\mathrm{m}^{3}$ & 184.11 & 262.67 & 48359.54 \\
\hline 010405001001 & beam slab & $\mathrm{m}^{3}$ & 361.00 & 361.80 & 130610.20 \\
\hline 010403002001 & rectangular beam & $\mathrm{m}^{3}$ & 81.66 & 361.57 & 29525.41 \\
\hline 010416001001 & steel bar & $\mathrm{t}$ & 225.84 & 2223.24 & 502104.11 \\
\hline 010702001001 & roofing rolls are waterproof & $\mathrm{m}^{2}$ & 356.74 & 96.89 & 34562.83 \\
\hline $\begin{array}{c}\cdots \cdots \\
\text { (measure project) }\end{array}$ & $\cdots \cdots$ & & $\cdots \cdots$ & $\cdots \cdots$ & $\cdots \cdots$ \\
\hline 060108000001 & formwork and bracket & item & 1.00 & 46824.83 & 46824.83 \\
\hline 060201000001 & $\begin{array}{l}\text { vertical transportation and } \\
\text { ultra-high transportation }\end{array}$ & item & 1.00 & 8892.63 & 8892.63 \\
\hline$\cdots \cdots$ & $\cdots \cdots$ & & $\cdots \cdots$ & $\cdots \cdots$ & $\cdots \cdots$ \\
\hline Total $\left(\mathrm{kgCO}_{2}\right.$-eq) & & & & & 3166876.38 \\
\hline
\end{tabular}


and equipment use at the operational stage can be converted into fossil energy and electric energy accounting. Considering the case building uses rooftop solar power as sustainable energy, the electricity generated can be supplied to the building, thus the resulting reduced carbon emissions should be deducted.

The operation simulation software called Green Building Studio in Revit2017 was harnessed to simulate and analyze the energy consumption at the operational stage, and the results of simulated fuel consumption and electricity consumption are shown in Figure 4 and Figure 5.

According to the algorithm above, the simulation result of Green Building Studio depicted that the carbon emissions consumed every year at the operational stage are $732 \mathrm{tCO}_{2}$-eq (see Figure 6). During the 50 years of operational stage, the carbon emissions are expected to be $36,600 \mathrm{tCO}_{2}$-eq.

\subsection{Estimated Carbon Emissions at the Demolition Stage}

Carbon emissions at the demolition stage are approximately estimated to be $10 \%$ of carbon emissions at the construction stage (based on Formula (7)). Many

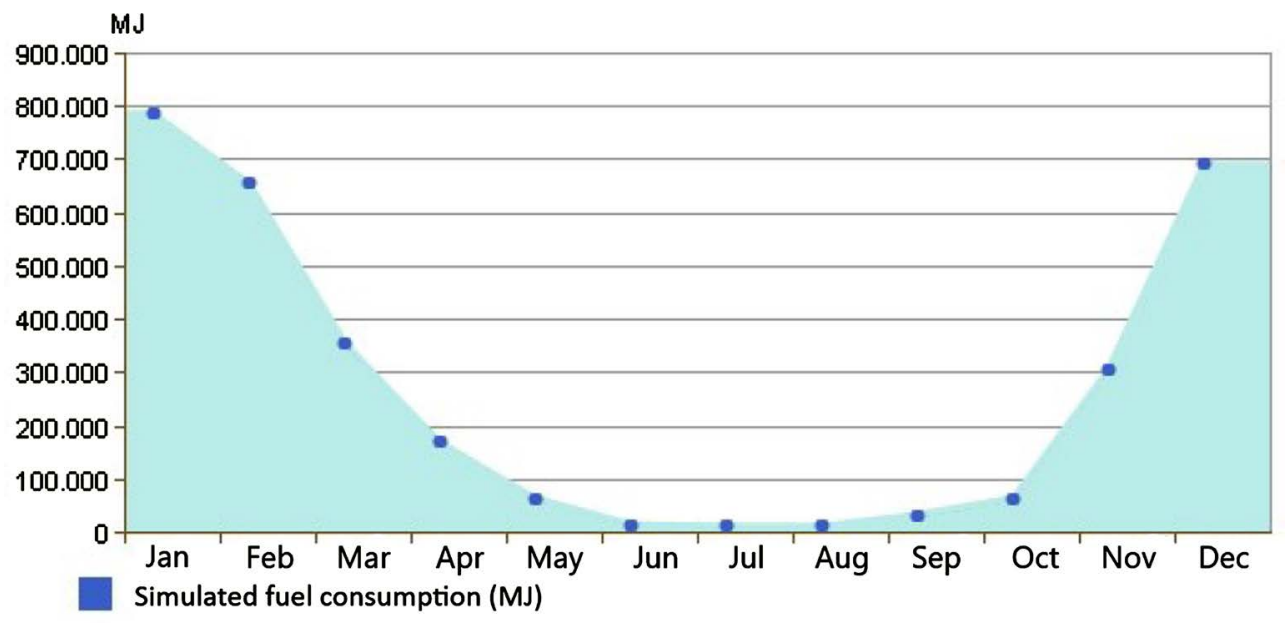

Figure 4. Simulated fuel consumption required for each month at the operational stage.

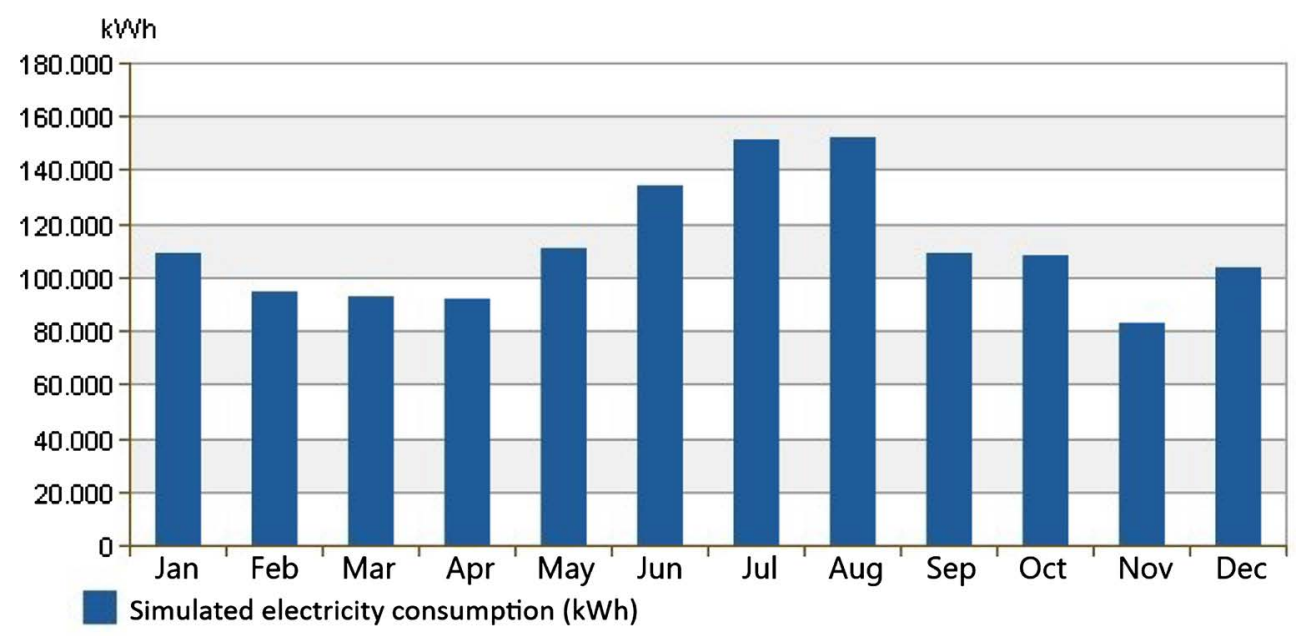

Figure 5. Simulated electricity consumption required for each month at the operational stage. 


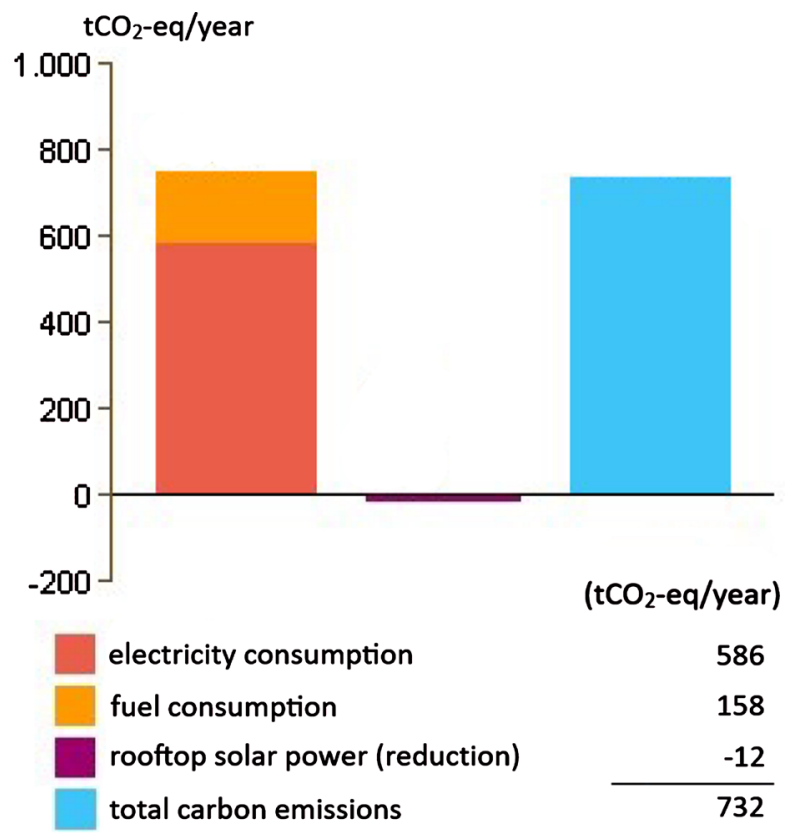

Figure 6. Carbon emissions from case building per year.

scholars maintained that the ratio of carbon emissions at the demolition stage to BLCCE is about $1 \%$ (Sartori \& Hestnes, 2007; Zhang \& Wang, 2015), as a consequence, the estimation of carbon emissions at this stage does not affect the results of BLCCE. According to Formula (7), the estimated value of carbon emissions at the demolition stage is $316.68 \mathrm{tCO}_{2}$-eq.

$$
C_{\text {dem }}=3166.87 \times 10 \%=316.69 \mathrm{tCO}_{2} \text {-eq }
$$

\subsection{Summary and Discussion}

Peng (2016) believed that average carbon emissions per working area per year of each building stage $C_{\mathrm{At}}\left(\mathrm{kgCO}_{2}-\mathrm{eq} /\left(\mathrm{m}^{2} \cdot \mathrm{y}\right)\right)$ is an important evaluation index of BLCCE, the formula for calculating $C_{\mathrm{At}}$ is concluded in Formula (8). In China, the expected year $(Y)$ of the construction, operational, and demolition stage of buildings is usually 2 years, 50 years, and 0.5 years, respectively (Peng, 2016; Wu, Yuan, Zhang, \& Bi, 2012; Zhang, Shen, \& Zhang, 2013).

$$
C_{\mathrm{At}(\mathrm{con}, \mathrm{ope}, \mathrm{dem}, \mathrm{tot})}=\frac{C_{(\text {con, ope,dem, tot })}}{Y \times G F A}
$$

The estimated results of carbon emissions at each stage were summarized and calculated, and the total estimation of BLCCE is $40,083.56 \mathrm{tCO}_{2}$-eq. In addition, average $\mathrm{CO}_{2}$-eq emissions per working area per year of construction, operational, demolition stage and life cycle (respectively is $C_{\mathrm{At}, \text { con }}, C_{\mathrm{At}, \mathrm{ope}}, C_{\mathrm{At}, \mathrm{dem}}, C_{\mathrm{At}, \mathrm{tot}}$ ) were calculated and listed in Table 8.

In BLCCE, the carbon emissions at operation stage account for the largest proportion (91.31\%) of the life cycle, while the $C_{\mathrm{At}, \mathrm{con}}$ at the construction stage is the highest, that is, the carbon emissions at the construction stage are the most concentrated. Therefore, in terms of low-carbon engineering design, engineers 
Table 8. Case building's life cycle carbon emissions.

\begin{tabular}{cccc}
\hline Stage & Carbon emission $\left(\mathrm{tCO}_{2}\right.$-eq) & Percentage $(\%)$ & $C_{\mathrm{At}}\left(\mathrm{kgCO}_{2}-\mathrm{eq} /\left(\mathrm{m}^{2} \cdot \mathrm{y}\right)\right)$ \\
\hline construction stage & 3166.87 & 7.90 & 248.69 \\
operational stage & 36600.00 & 91.31 & 114.97 \\
demolition stage & 316.69 & 0.79 & 99.48 \\
total & 40083.56 & 100.00 & 119.91 \\
\hline
\end{tabular}

should focus on carbon emissions at the operational stage and the construction stage.

\section{Discussion}

\subsection{Application Scope and Limitations}

As a hot spot in the field of architecture, engineering, and construction, BIM will be the mainstream delivery option in the future (Cao et al., 2015). Combined with BIM and LCA, this paper proposed an estimation of BLCCE method, which is rapidness and convenience. As long as the BIM designed by engineers can be acquired, the simulation results of the bill of quantities and operational energy consumption can be quickly obtained, and then the BLCCE can also be simulated.

However, creating BIM takes a long time. Due to various other factors, the current delivery option in China is still stuck in the CAD drawings (Cao et al., 2015). Secondary creating BIM based on CAD drawings will also lead to more serious work delays. Moreover, there is component loss in the introduction of Revit2017 into GTJ2018, and repairing BIM engineering quantities model also result in a waste of time and effort. These factors may reduce the rapidity of the method of this paper.

It is particularly noteworthy that there is still a certain gap between the estimation method and the actual carbon emission calculation, which is mainly evidenced by follows: 1) since the data of refurbishment is difficult to obtain, the carbon emission of this part is neglected in the estimation model; 2) in the case, the design phase lacks the design scheme of facilities and equipment, so the carbon emission of this part is ignored; 3) there are many uncertainties during operation (such as operation schedule, HVAC parameters, thermal conductivity of insulation material) which will lead to distortion of energy consumption simulation; 4) the missing carbon emission coefficient of some materials in China is also the reason for the deviation of the estimation results.

\subsection{Comparison with Other Studies}

In previous studies, many scholars have studied the BLCCE of villas, residences and office buildings. In order to grasp the characteristics of the hospital building's life cycle carbon emissions, the study compared the hospital building in this case with the other studies of some scholars. To avoid the differences of carbon emission coefficient caused by different countries, the scopes of cases 
were all framed in China. Additionally, the selected cases met the following conditions: 2 years in the construction stage, 50 years in the operational stage, and 0.5 years in the demolition stage, which guaranteed the comparability between these cases.

According to the studies on villas (Yang et al., 2018), residential building (Li, Cui, \& Lu, 2016; Zhang \& Wang, 2015; Zhang, Zheng, Zhang, Chen, \& Wang, 2016), office buildings (Peng, 2016; Zhang \& Wang, 2015), the percentage Per (\%) and carbon emissions per working area per year $C_{\mathrm{At}}\left(\mathrm{kgCO}_{2}\right.$-eq $\left./\left(\mathrm{m}^{2} \cdot \mathrm{y}\right)\right)$ at each stage were calculated. The calculation results are shown in Table 9.

In terms of the percentage of carbon emissions at each stage, carbon emissions account for $7.9 \%$ to $35.32 \%$ of the BLCCE at the construction stage, $63.26 \%$ to $91.31 \%$ at the operational stage, and $0.27 \%$ to $1.94 \%$ at the demolition stage, respectively. The demolition stage account for a small slice of BLCCE (almost negligible), while the construction stage and operational stage constitute $98.06 \%$ to 99.73\% of BLCCE in total. Hence the low-carbon design should be optimized at the construction stage and the operational stage.

In the aspect of the average carbon emissions per working area per year at the construction stage $\left(C_{\mathrm{At}, \text { con }}\right)$, the $C_{\mathrm{At}, \text { con }}$ of hospital is in the middle range of all case. The highest $C_{\mathrm{At}, \mathrm{con}}$ indicator is $357.33 \mathrm{kgCO}_{2}-\mathrm{eq} /\left(\mathrm{m}^{2} \cdot \mathrm{y}\right)$ of Case 2 , which is mainly because Case 2 is a villa with luxurious and complicated decoration. Correspondingly, the $C_{\mathrm{At}, \mathrm{con}}$ of low-rise residential building with general decoration (see Case 5) is lowest within all case. Also, as the number of layers adds, the structural design grows harder, which leads to a growth in the amount of material used per square and an increase in $C_{\mathrm{At}, \mathrm{con}}$.

From the perspective of $C_{\mathrm{At}, o p e}$, the hospital building in this study is obviously higher than villas, residences, and office buildings (see Case 2 - 9). This may be due to the following factors: 1 ) the hospital building, as a public building that bears the burden of the whole city's medical system, serves the population of the entire city. As a result, it carries far more customers per construction area than that of villas, residences, and office buildings; 2) patients in hospital have higher

Table 9. Percentage and $C_{\mathrm{At}}$ at each stage.

\begin{tabular}{|c|c|c|c|c|c|c|c|c|c|c|c|}
\hline & Authors & Architectural type & Structure system & Floor & Per $_{\text {con }}$ & Per $_{\text {ope }}$ & $\operatorname{Per}_{\mathrm{dem}}$ & $C_{\mathrm{At}, \mathrm{con}}$ & $C_{\text {At,ope }}$ & $C_{\mathrm{At}, \mathrm{dem}}$ & $C_{\mathrm{At}, \text { tot }}$ \\
\hline 1 & this study & hospital & reinforced concrete & 4 & 7.90 & 91.31 & 0.79 & 248.69 & 114.97 & 99.48 & 119.91 \\
\hline 2 & Yang et al. (2018) & villa & brick-concrete & 2 & 23.87 & 75.35 & 0.78 & 357.33 & 45.11 & 46.42 & 57.02 \\
\hline 3 & Peng (2016) & office building & reinforced concrete & 15 & 12.64 & 85.43 & 1.94 & 321.00 & 86.76 & 196.59 & 96.73 \\
\hline 4 & Y. Zhang et al. (2016) & residential building & reinforced concrete & 15 & 27.17 & 72.56 & 0.27 & 191.18 & 20.42 & 7.70 & 26.80 \\
\hline 5 & D. Li et al. (2016) & residential building & masonry-concrete & 4 & 35.32 & 63.26 & 1.42 & 168.04 & 12.04 & 27.02 & 18.12 \\
\hline 6 & X. Zhang and Wang (2015) & residential building & brick-concrete & 6 & 17.16 & 82.48 & 0.36 & 310.50 & 59.70 & 26.00 & 68.93 \\
\hline 7 & X. Zhang and Wang (2015) & residential building & masonry-concrete & 6 & 14.52 & 85.16 & 0.31 & 254.50 & 59.70 & 22.00 & 66.76 \\
\hline 8 & X. Zhang and Wang (2015) & residential building & reinforced concrete & 16 & 16.41 & 83.29 & 0.30 & 322.00 & 67.70 & 24.00 & 77.41 \\
\hline 9 & X. Zhang and Wang (2015) & office building & reinforced concrete & 28 & 14.82 & 84.91 & 0.27 & 307.50 & 70.46 & 22.00 & 79.03 \\
\hline
\end{tabular}


requirements for temperature and ventilation, which increases the energy consumption and carbon emissions; 3 ) some departments of the hospital (for example, the emergency department) are open in 24 hours, which cause more energy consumption and produce more carbon emissions than other building that are dormant at night.

$C_{\mathrm{At} \text { tot }}$ is heavily affected by carbon emissions at the operational stage, so the $C_{\mathrm{At}, \mathrm{tot}}$, of the hospital building is still higher than other cases. The explanation is that the operational stage is 50 years, while the construction stage and demolition stage are only 2 years and 0.5 years, respectively.

\section{Conclusion}

BIM and LCA were applied to estimate the BLCCE in this study, which is proved to be quickly and effectively in the engineering design stage. In addition, this paper took a Chinese hospital building as an example to test the feasibility of the method and filled the research gap of the BLCCE among hospital buildings. The results of this case study provided a reference value for similar hospitals under the same climate and economic situations.

In the calculation results of this study, the BLCCE of case building is 40083.56 $\mathrm{tCO}_{2}$-eq, and average carbon emissions per working area per year are 119.91 $\mathrm{kgCO}_{2}-\mathrm{eq} /\left(\mathrm{m}^{2} \cdot \mathrm{y}\right)$ in the building's life cycle. The carbon emissions at the construction stage, the operational stage, and the demolition stage constitute $7.90 \%$, $91.31 \%$ and $0.79 \%$ of BLCCE, separately. The $C_{\mathrm{At}, \mathrm{ope}}$ of hospital is apparently higher than that of villas, residences, and office buildings. This study ascribed this finding to the following three principal elements: 1) large population in need of service; 2) long daily operational hours; 3 ) high comfort requirement of the patient.

The estimation method in this paper is rapid and effective. However, as an estimation method, it has certain limitations, and mainly include: 1) due to the information lack of refurbishment and facilities, this part of carbon emission is neglected in estimation; 2) there are component losses in process of Revit2017 into GTJ2018, and this issue consumes plenty of time to check and replenish the modeling; 3) the carbon emissions coefficient of some materials in China is missing, or greatly different from the international standard, which leads that estimated result is quite at odds with the actual value.

To compensate for the above shortcomings, future studies need to develop an estimation method about refurbishment. The problems of incompatibility between BIM software also need to be settled. Furthermore, horizontal comparisons of BLCCE between more building type (school, shopping mall, urban complex, etc.) are also the focus of our attention henceforward.

\section{Acknowledgements}

This paper was supported by College Students Innovation and Entrepreneurship Training Program (2016CXCY201) of Hefei University of Technology. Project 
name: research on building's carbon emission and integrated system based on city perspective.

\section{Conflicts of Interest}

The authors declare that there is no conflict of interest regarding the publication of this paper.

\section{References}

Baek, C., Tae, S., Kim, R., \& Shin, S. (2016). Life Cycle $\mathrm{CO}_{2}$ Assessment by Block Type Changes of Apartment Housing. Sustainability, 8, 752.

https://doi.org/10.3390/su8080752

Basbagill, J., Flager, F., Lepech, M., \& Fischer, M. (2013). Application of Life-Cycle Assessment to Early Stage Building Design for Reduced Embodied Environmental Impacts. Building and Environment, 60, 81-92.

https://doi.org/10.1016/j.buildenv.2012.11.009

Cabeza, L. F., Rincón, L., Vilariño, V., Pérez, G., \& Castell, A. (2014). Life Cycle Assessment (LCA) and Life Cycle Energy Analysis (LCEA) of Buildings and the Building Sector: A Review. Renewable and Sustainable Energy Reviews, 29, 394-416. https://doi.org/10.1016/j.rser.2013.08.037

Cai, X., Wang, M., \& Fu, B. (2010). Residential Construction Analysis and Measures for Energy Conservation and Emissions Reduction of Carbon Emissions. Journal of Disaster Prevention and Mitigation Engineering, 30, 428-431. (In Chinese)

Cao, D., Wang, G., Li, H., Skitmore, M., Huang, T., \& Zhang, W. (2015). Practices and Effectiveness of Building Information Modelling in Construction Projects in China. Automation in Construction, 49, 113-122. https://doi.org/10.1016/j.autcon.2014.10.014

Cubi, E., Doluweera, G., \& Bergerson, J. (2015). Incorporation of Electricity GHG Emissions Intensity Variability into Building Environmental Assessment. Applied Energy, 159, 62-69. https://doi.org/10.1016/j.apenergy.2015.08.091

Gan, V. J. L., Deng, M., Tse, K. T., Chan, C. M., Lo, I. M. C., \& Cheng, J. C. P. (2018). Holistic BIM Framework for Sustainable Low Carbon Design of High-Rise Buildings. Journal of Cleaner Production, 195, 1091-1104.

https://doi.org/10.1016/j.jclepro.2018.05.272

Gustavsson, L., Joelsson, A., \& Sathre, R. (2010). Life Cycle Primary Energy Use and Carbon Emission of an Eight-Storey Wood-Framed Apartment Building. Energy and Buildings, 42, 230-242. https://doi.org/10.1016/j.enbuild.2009.08.018

Häkkinen, T., Kuittinen, M., Ruuska, A., \& Jung, N. (2015). Reducing Embodied Carbon during the Design Process of Buildings. Journal of Building Engineering, 4, 1-13. https://doi.org/10.1016/j.jobe.2015.06.005

Han, G., Srebric, J., \& Enache-Pommer, E. (2014). Variability of Optimal Solutions for Building Components Based on Comprehensive Life Cycle Cost Analysis. Energy and Buildings, 79, 223-231. https://doi.org/10.1016/j.enbuild.2013.10.036

Hua, H., Wang, X.-M., Deng, P., He, J.-Q., Chen, C., Zeng, B.-B., \& Zhang, Y. (2014). Study on Low-Carbon Design Analysis and Carbon Emission Measure of Public Building Based on BIM. Journal of Civil Engineering and Management, 31, 62-67. (In Chinese)

Inyim, P., Rivera, J., \& Zhu, Y. (2014). Integration of Building Information Modeling and Economic and Environmental Impact Analysis to Support Sustainable Building Design. 
Journal of Management in Engineering, 31.

https://doi.org/10.1061/(ASCE)ME.1943-5479.0000308

Klüppel, H.-J. (1998). ISO 14041: Environmental Management-Life Cycle Assessment-Goal and Scope Definition-Inventory Analysis. The International Journal of Life Cycle Assessment, 3, 301. https://doi.org/10.1007/BF02979337

Klüppel, H.-J. (2005). The Revision of ISO Standards 14040-3-ISO 14040: Environmental Management-Life Cycle Assessment-Principles and Framework-ISO 14044: Environmental Management-Life Cycle Assessment-Requirements and Guidelines. The International Journal of Life Cycle Assessment, 10, 165-165. https://doi.org/10.1065/lca2005.03.001

Lee, J., Tae, S., \& Kim, R. (2018). A Study on the Analysis of $\mathrm{CO}_{2}$ Emissions of Apartment Housing in the Construction Process. Sustainability, 10, 365.

https://doi.org/10.3390/su10020365

Li, D., Cui, P., \& Lu, Y. (2016). Development of an Automated Estimator of Life-Cycle Carbon Emissions for Residential Buildings: A Case Study in Nanjing, China. Habitat International, 57, 154-163. https://doi.org/10.1016/j.habitatint.2016.07.003

Li, X., Zhu, Y., \& Zhang, Z. (2010). An LCA-Based Environmental Impact Assessment Model for Construction Processes. Building and Environment, 45, 766-775. https://doi.org/10.1016/j.buildenv.2009.08.010

Maia, L., Mêda, P., \& Freitas, J. G. (2015). BIM Methodology, a New Approach-Case Study of Structural Elements Creation. Procedia Engineering, 114, 816-823. https://doi.org/10.1016/j.proeng.2015.08.032

Norris, G. A. (2001). Integrating Life Cycle Cost Analysis and LCA. International Journal of Life Cycle Assessment, 6, 118-120.

Peng, C. (2016). Calculation of a Building's Life Cycle Carbon Emissions Based on Ecotect and Building Information Modeling. Journal of Cleaner Production, 112, 453-465. https://doi.org/10.1016/j.jclepro.2015.08.078

Penttilä, H. (2006). Describing the Changes in Architectural Information Technology to Understand Design Complexity and Free-Form Architectural Expression. Electronic Journal of Information Technology in Construction, 11, 395-408.

Ramesh, T., Prakash, R., \& Shukla, K. K. (2010). Life Cycle Energy Analysis of Buildings: An Overview. Energy and Buildings, 42, 1592-1600. https://doi.org/10.1016/j.enbuild.2010.05.007

Rezaei, F., Bulle, C., \& Lesage, P. (2019). Integrating Building Information Modeling and Life Cycle Assessment in the Early and Detailed Building Design Stages. Building and Environment, 153, 158-167. https://doi.org/10.1016/j.buildenv.2019.01.034

Roh, S., \& Tae, S. (2017). An Integrated Assessment System for Managing Life Cycle $\mathrm{CO}_{2}$ Emissions of a Building. Renewable and Sustainable Energy Reviews, 73, 265-275. https://doi.org/10.1016/j.rser.2017.01.139

Santos, R., Costa, A. A., Silvestre, J. D., \& Pyl, L. (2019). Integration of LCA and LCC Analysis within a BIM-Based Environment. Automation in Construction, 103, 127-149. https://doi.org/10.1016/j.autcon.2019.02.011

Sartori, I., \& Hestnes, A. G. (2007). Energy Use in the Life Cycle of Conventional and Low-Energy Buildings: A Review Article. Energy and Buildings, 39, 249-257. https://doi.org/10.1016/j.enbuild.2006.07.001

Shadram, F., Johansson, T. D., Lu, W., Schade, J., \& Olofsson, T. (2016). An Integrated BIM-Based Framework for Minimizing Embodied Energy during Building Design. Energy and Buildings, 128, 592-604. https://doi.org/10.1016/j.enbuild.2016.07.007 
Shin, Y. S., \& Cho, K. (2015). BIM Application to Select Appropriate Design Alternative with Consideration of LCA and LCCA. Mathematical Problems in Engineering, 2015, Article ID: 281640. https://doi.org/10.1155/2015/281640

Soust-Verdaguer, B., Llatas, C., \& García-Martínez, A. (2017). Critical Review of Bim-Based LCA Method to Buildings. Energy and Buildings, 136, 110-120. https://doi.org/10.1016/j.enbuild.2016.12.009

Turner, L. K., \& Collins, F. G. (2013). Carbon Dioxide Equivalent (CO2-e) Emissions: A Comparison between Geopolymer and OPC Cement Concrete. Construction and Building Materials, 43, 125-130. https://doi.org/10.1016/j.conbuildmat.2013.01.023

Wan Omar, W.-M.-S., Doh, J.-H., \& Panuwatwanich, K. (2014). Variations in Embodied Energy and Carbon Emission Intensities of Construction Materials. Environmental Impact Assessment Review, 49, 31-48. https://doi.org/10.1016/j.eiar.2014.06.003

Wiedmann, T., \& Minx, J. (2008). A Definition of “Carbon Footprint”. Ecological Economics Research Trends, 1, 1-11.

Wong, J. K. W., \& Kuan, K. L. (2014). Implementing "BEAM plus" for BIM-Based Sustainability Analysis. Automation in Construction, 44, 163-175.

https://doi.org/10.1016/j.autcon.2014.04.003

Wong, J. K. W., \& Zhou, J. (2015). Enhancing Environmental Sustainability over Building Life Cycles through Green BIM: A Review. Automation in Construction, 57, 156-165. https://doi.org/10.1016/j.autcon.2015.06.003

Wu, H. J., Yuan, Z. W., Zhang, L., \& Bi, J. (2012). Life Cycle Energy Consumption and $\mathrm{CO}_{2}$ Emission of an Office Building in China. The International Journal of Life Cycle Assessment, 17, 105-118. https://doi.org/10.1007/s11367-011-0342-2

Yang, X., Hu, M., Wu, J., \& Zhao, B. (2018). Building-Information-Modeling Enabled Life Cycle Assessment, a Case Study on Carbon Footprint Accounting for a Residential Building in China. Journal of Cleaner Production, 183, 729-743.

https://doi.org/10.1016/j.jclepro.2018.02.070

Zhang, X., \& Wang, F. (2015). Life-Cycle Assessment and Control Measures for Carbon Emissions of Typical Buildings in China. Building and Environment, 86, 89-97. https://doi.org/10.1016/j.buildenv.2015.01.003

Zhang, X., Shen, L., \& Zhang, L. (2013). Life Cycle Assessment of the Air Emissions during Building Construction Process: A Case Study in Hong Kong. Renewable and Sustainable Energy Reviews, 17, 160-169. https://doi.org/10.1016/j.rser.2012.09.024

Zhang, Y., Zheng, X., Zhang, H., Chen, G., \& Wang, X. (2016). Carbon Emission Analysis of a Residential Building in China through Life Cycle Assessment. Frontiers of Environmental Science and Engineering, 10, 150-158. https://doi.org/10.1007/s11783-014-0684-7

Zhong, P. (2005). Study of Building Life-Cycle Energy Use and Relevant Environmental Impacts. M.D. Thesis, Chengdu: Sichuan University. (In Chinese)

Zhu, J., Chew, D. A. S., Lv, S., \& Wu, W. (2013). Optimization Method for Building Envelope Design to Minimize Carbon Emissions of Building Operational Energy Consumption Using Orthogonal Experimental Design (OED). Habitat International, 37, 148-154. https://doi.org/10.1016/j.habitatint.2011.12.006 